\title{
A Tauberian Theorem for Double Cesàro Summability Method
}

\author{
Bidu Bhusan Jena, ${ }^{1}$ Susanta Kumar Paikray, ${ }^{1}$ and Umakanta Misra ${ }^{2}$ \\ ${ }^{1}$ Department of Mathematics, VSS University of Technology, Burla 768018, India \\ ${ }^{2}$ Department of Mathematics, NIST, Palur Hills, Golanthara 761008, India \\ Correspondence should be addressed to Susanta Kumar Paikray; skpaikray_math@vssut.ac.in
}

Received 24 February 2016; Revised 12 April 2016; Accepted 27 April 2016

Academic Editor: Syed Abdul Mohiuddine

Copyright (C) 2016 Bidu Bhusan Jena et al. This is an open access article distributed under the Creative Commons Attribution License, which permits unrestricted use, distribution, and reproduction in any medium, provided the original work is properly cited.

We have generalized Littlewood Tauberian theorems for $(C, k, r)$ summability of double sequences by using oscillating behavior and de la Vallée-Poussin mean. Further, the generalization of $(C, r)$ summability from $(C, k, r)$ summability is given as corollaries which were earlier established by the authors.

\section{Introduction}

Let $u=\left(u_{m n}\right)$ be a double real sequence. We define $\Delta_{n} u_{m n}=$ $u_{m n}-u_{m, n-1}, \Delta_{m} u_{m n}=u_{m n}-u_{m-1, n}$, and $\Delta_{m, n} u_{m n}=u_{m n}-$ $u_{m-1, n}-u_{m, n-1}+u_{m-1, n-1}$.

A double sequence $\left(u_{m n}\right)$ is said to be bounded if there exists a finite real number $C>0$ such that $\left|u_{m n}\right| \leq C, \forall m, n \in$ $Z^{+}$. Let us write

$$
\begin{aligned}
\sigma_{m n}^{(11)}(u) & =\frac{1}{(m+1)(n+1)} \sum_{p=0}^{m} \sum_{q=0}^{n} u_{p q} \\
& =\sum_{p=1}^{m} \sum_{q=1}^{n} \frac{V_{p q}^{(11)}}{p q}+u_{00}
\end{aligned}
$$

(see [1]),

$$
\begin{aligned}
& \sigma_{m n}^{(10)}(u)=\frac{1}{m+1} \sum_{p=0}^{m} u_{p n}, \\
& \sigma_{m n}^{(01)}(u)=\frac{1}{n+1} \sum_{q=0}^{n} u_{m q} .
\end{aligned}
$$

Then, we say that a double sequence $u=\left(u_{m n}\right)$ is $(C, 1,1)$ summable to $s$ if $\sigma_{m n}^{(11)}(u)$ converges to $s$, as $m, n \rightarrow \infty$. Similarly, we say that it is $(C, 1,0)$ summable to $s$ if $\sigma_{m n}^{(10)}(u)$ converges to $s$ as $m, n \rightarrow \infty$ and $(C, 0,1)$ summable to $s$ if $\sigma_{m n}^{(10)}(u)$ converges to $s$ as $m, n \rightarrow \infty$. For all nonnegative integers $k$ and $r$, we define $\sigma_{m n}^{(k r)}(u)$ as follows:

$$
\begin{aligned}
& \sigma_{m n}^{(k r)}(u) \\
& = \begin{cases}\frac{1}{(m+1)(n+1)} \sum_{p=0}^{m} \sum_{q=0}^{n} \sigma_{p q}^{(k-1, r-1)}(u) & \text { for } k, r \geq 1, \\
u_{m n} & \text { for } k, r=0 .\end{cases}
\end{aligned}
$$

A double sequence $u=\left(u_{m n}\right)$ is said to be $(C, k, r)$ summable to $s$ if $\sigma_{m n}^{(k r)}(u)$ converges to $s$. If $k=1$ and $r=1$, then $(C, k, r)$ summability reduces to $(C, 1,1)$ summability. Again, if $k \neq 0$ and $r=0$, then $(C, k, r)$ summability reduces to $(C, k, 0)$ summability. Further, if $k=0$ and $r \neq 0$, then $(C, k, r)$ summability reduces to $(C, 0, r)$ summability. Here, Cesàro summability of $u=\left(u_{m n}\right)$ refers to $(C, k, r)$ summability of $u=\left(u_{m n}\right)$. It may also be noted that the convergence of a double sequence $u=\left(u_{m n}\right)$ implies the Cesàro summability of $u=\left(u_{m n}\right)$, but the converse is not generally true.

For example, consider a function $f(x, y)=e^{2 x} \sin (3 y)$ : the sequence $\left(u_{m n}\right)$, which is the sequence of coefficients in the Taylor series expansion of the function $f(x, y)$ about origin, is Cesàro summable but not convergent.

For the proof of the converse part, certain conditions are presented in terms of oscillatory behavior of double sequence $u=\left(u_{m n}\right)$. 
Let us define $\left(u_{m n}\right)$ as

$$
u_{m n}=V_{m n}^{(11)}+\sum_{p=1}^{m} \sum_{q=1}^{n} \frac{V_{p q}^{(11)}}{p q}+u_{00}, \quad(m, n=1,2, \ldots) \text {, }
$$

where

$$
\begin{aligned}
u_{m n}-\sigma_{m n}^{11}(u) & =V_{m n}^{(11)}(\Delta u) \\
& =\frac{1}{(m+1)(n+1)} \sum_{p=0}^{m} \sum_{q=0}^{n} p q\left(\Delta_{p, q} u_{p q}\right)
\end{aligned}
$$

(see [2]).

Moreover, in analogy to Kronecker identity for a single sequence, we can write

$$
\begin{aligned}
& V_{m n}^{(1,0)}(\Delta u)=\frac{1}{(m+1)} \sum_{p=0}^{m} p\left(\Delta_{p}, u_{p, n}\right), \\
& V_{m n}^{(0,1)}(\Delta u)=\frac{1}{(n+1)} \sum_{q=0}^{n} q\left(\Delta_{q}, u_{m, q}\right)
\end{aligned}
$$

as the $(C, 1,0)$ mean of the sequence $m \Delta_{m} u_{m n}$ and the $(C, 0,1)$ mean of the sequence " $n \Delta_{n} u_{m n}$," respectively.

Further, as the sequence $V_{m n}^{(11)}\left(\Delta_{m n} u_{m n}\right)$ is the $(C, 1,1)$ mean of the sequence $m n\left(\Delta_{m n} u_{m n}\right)$, the sequence $m n\left(\Delta_{m n} u_{m n}\right)$ is $(C, 1,1)$ summable to $s$ whenever $V_{m n}^{(11)}\left(\Delta_{m n} u_{m n}\right)$ converges to $s$ as $m, n \rightarrow \infty$. For all nonnegative integers $k$ and $r$, let us define $V_{m n}^{(k r)}(\Delta u)$ as follows:

$$
\begin{aligned}
& V_{m n}^{(k r)}(\Delta u) \\
& = \begin{cases}\frac{1}{(m+1)(n+1)} \sum_{p=0}^{m} \sum_{q=0}^{n} V_{p q}^{(k-1, r-1)}(\Delta u) & \text { for } k, r \geq 1, \\
m n\left(\Delta_{m, n} u_{m n}\right) & \text { for } k, r=0 .\end{cases}
\end{aligned}
$$

The sequence $m n\left(\Delta_{m n} u_{m n}\right)$ is said to be $(C, k, r)$ summable to $s$ if $V_{m n}^{(k r)}\left(\Delta_{m n} u_{m n}\right)$ converges to $s$ as $m, n \rightarrow \infty$. In particular, if $k=1$ and $r=1$, then $(C, k, r)$ summability reduces to $(C, 1,1)$ summability. Again, if $k \neq 0$ and $r=0$, then $(C, k, r)$ summability reduces to $(C, k, 0)$ summability. Further, if $k=0$ and $r \neq 0$, then $(C, k, r)$ summability reduces to $(C, 0, r)$ summability.

Then, the de la Vallée-Poussin mean of double real sequence $\left(u_{m n}\right)$ is defined by

$$
\tau_{m n}(u)=\frac{1}{([\lambda m]-m)([\lambda n]-n)} \sum_{i=m+1}^{[\lambda m]} \sum_{j=n+1}^{[\lambda n]} u_{i j},
$$

for sufficiently large nonnegative integers $m, n$ and $\lambda>1$, and

$$
\tau_{m n}(u)=\frac{1}{(m-[\lambda m])(n-[\lambda n])} \sum_{i=\lambda m+1}^{m} \sum_{j=\lambda n+1}^{n} u_{i j},
$$

for sufficiently large nonnegative integers $m, n$ and $0<\lambda<1$.
A single sequence $u=\left(u_{n}\right)$ is slowly oscillating [3] if

$$
\lim _{\lambda \rightarrow 1^{+}} \lim \sup _{n} \max _{n \leq k \leq[\lambda n]}\left|u_{k}-u_{n}\right|=0 .
$$

A double sequence $u=\left(u_{m n}\right)$ is slowly oscillating [4] if

$$
\begin{aligned}
& \lim _{\lambda \rightarrow 1^{+}} \lim _{m, n} \sup _{m+1, n+1 \leq i, j \leq[\lambda m, \lambda n]}\left|\sum_{x=m+1}^{i} \sum_{y=n+1}^{j} \Delta_{x, y} u_{x y}\right| \\
& \quad=0 .
\end{aligned}
$$

In an earlier paper by Jena et. al. [5], a proof of the generalized Littlewood Tauberian theorem by Cesàro summability method has been established. For a proof of Littlewood Tauberian theorem differently, the paper of Çanak and Totur [6] and Çanak [7-9] can be referred to. Also, a similar result was introduced earlier by Çanak [10] under the consideration of improper integral. Recently, Totur [4] has introduced Littlewood Tauberian theorem by $(C, 1,1)$ mean for double real sequence.

In the proposed paper, with certain novelty, we have generalized it for $(C, k, r)$ summability of a double real sequence defined in (4).

\section{Known Results}

Theorem 1 (see [4]). If the sequence $\left(u_{m n}\right)$ is $(C, 1,1)$ summable to $s$ and $\left(u_{m n}\right)$ is slowly oscillating (in the sense of $(1,1))$, then $\lim _{m, n \rightarrow \infty} u_{m n}=s$.

Corollary 2 (see [5]). If the sequence $\left(u_{n}\right)$ is $(C, 1)$ summable to $s$ and $\left(u_{n}\right)$ is slowly oscillating, then $\lim _{n \rightarrow \infty} u_{n}=s$.

Theorem 3 (see [4]). If the sequence $u=\left(u_{m n}\right)$ is $(C, 1,1)$ summable to $s$ and $V_{m n}^{(11)}\left(\Delta_{m n} u_{m n}\right)$ is slowly oscillating, then $\lim _{m, n \rightarrow \infty} u_{m n}=s$.

Corollary 4 (see [5]). If the sequence $\left(u_{n}\right)$ is $(C, 1)$ summable to $s$ and $V_{m n}^{(1,0)}(\Delta u)$ is slowly oscillating, then $\lim _{n \rightarrow \infty} u_{n}=s$.

\section{Main Result}

Theorem 5. If $\left(u_{m n}\right)$ is $(C, k, r)$ summable to $s$ and $\left(u_{m n}\right)$ is slowly oscillating, then $\lim _{m, n \rightarrow \infty} u_{m n}=s$.

To prove the above theorem, we need the help of the following lemmas.

Lemma 6. A double sequence $u=\left(u_{m n}\right)$ is slowly oscillating if and only if $V_{m n}^{(11)}$ is slowly oscillating and bounded.

Proof. Let $u=\left(u_{m n}\right)$ be slowly oscillating. Initially, let us show that $V_{m n}^{(11)}=O(1)$.

We have by definition of slow oscillation, for $\lambda>1$,

$$
\lim _{\lambda \rightarrow 1^{+}} \lim _{m, n} \max _{m+1, n+1 \leq i, j \leq[\lambda m, \lambda n]}\left|\sum_{x=m+1}^{i} \sum_{y=n+1}^{j} \Delta_{x, y} u_{x y}\right|
$$

$$
=0 \text {, }
$$


and let us rewrite the finite $\operatorname{sum} \sum_{i=1}^{m} \sum_{j=1}^{n} i j \Delta u_{i j}$ as the series $\sum_{x=0}^{\infty} \sum_{y=0}^{\infty} \sum_{m / 2^{x+1}, n / 2^{y+1} \leq i, j<m / 2^{x}, n / 2^{y}} i j \Delta u_{i j}$.

Clearly,

$$
\begin{aligned}
& \left|\sum_{i=1}^{m} \sum_{j=1}^{n} i j \Delta u_{i j}\right| \leq\left|\sum_{x=0}^{\infty} \sum_{y=0}^{\infty} \sum_{m / 2^{x+1}, n / 2^{y+1} \leq i, j<m / 2^{x}, n / 2^{y}} i j \Delta u_{i j}\right| \\
& \quad \leq\left(\sum_{x=0}^{\infty} \sum_{y=0}^{\infty} \frac{m n}{2^{x+y}}\right) \\
& \cdot \max _{m / 2^{x+1}+1, n / 2^{y+1}+1 \leq i, j \leq\left[\lambda m / 2^{i+1}, \lambda n / 2^{j+1}\right]}\left|\sum_{x=m / 2^{x+1}+1}^{i} \sum_{y=n / 2^{y+1}+1}^{j} \Delta_{x, y} u_{x y}\right| \\
& \quad \leq m n C\left(\sum_{x=0}^{\infty} \sum_{y=0}^{\infty} \frac{1}{2^{x+y}}\right)=m n C^{*},
\end{aligned}
$$

where $C^{*}>0$.

Consequently, we have

$$
\begin{aligned}
V_{m n}^{(11)}(\Delta u) & =\frac{1}{(m+1)(n+1)} \sum_{p=0}^{m} \sum_{q=0}^{n} p q\left(\Delta_{p, q} u_{p q}\right) \\
& =O(1), \quad \text { as } m, n \longrightarrow \infty .
\end{aligned}
$$

Since $\left\{\sigma_{m n}^{(11)}(u)=\sum_{p=1}^{m} \sum_{q=1}^{n}\left(V_{p q}^{(11)} / p q\right)+u_{00}\right\}$ is slowly oscillating, $V_{m n}^{(11)}$ is slowly oscillating.

To prove the converse part, consider $V_{m n}^{(11)}$ to be bounded and slowly oscillating. Now, the boundedness of $V_{m n}^{(11)}$ implies that $\sigma_{m n}^{(11)}(u)$ is slowly oscillating. Further, $V_{m n}^{(11)}$ is slowly oscillating, so, by Kronecker identity $(5),\left(u_{m n}\right)$ is slowly oscillating.

This completes the proof of Lemma 6.

Next, we represent the difference $\left(u_{m n}-\sigma_{m n}^{(11)}(u)\right)$ under two different cases in the following lemma.

Lemma 7 (see [1]). Let $u=\left(u_{m n}\right)$ be a sequence of real numbers with $m, n$ sufficiently large; then one has the following:

(i) $\operatorname{For} \lambda>1$,

$$
\begin{aligned}
u_{m n} & -\sigma_{m n}^{(11)}(u) \\
= & \frac{([\lambda m]+1)([\lambda n]+1)}{([\lambda m]-m)([\lambda n]-n)}\left(\sigma_{[\lambda m],[\lambda n]}^{(11)}(u)\right. \\
- & \left.\sigma_{[\lambda m], n}^{(11)}(u)-\sigma_{m,[\lambda n]}^{(11)}(u)+\sigma_{m n}^{(11)}(u)\right) \\
+ & \frac{[\lambda m]+1}{[\lambda n]-m}\left(\sigma_{[\lambda m], n}^{(11)}(u)-\sigma_{m, n}^{(11)}(u)\right) \\
+ & \frac{[\lambda n]+1}{[\lambda m]-m}\left(\sigma_{m,[\lambda n]}^{(11)}(u)-\sigma_{m n}^{(11)}(u)\right) \\
- & \frac{1}{([\lambda m]-m)([\lambda n]-n)} \sum_{i=m+1}^{[\lambda m]} \sum_{j=n+1}^{[\lambda n]}\left(u_{i j}-u_{m n}\right) .
\end{aligned}
$$

(ii) For $0<\lambda<1$,

$$
\begin{aligned}
& u_{m n}-\sigma_{m n}^{(1)}(u)=\frac{([\lambda m]+1)([\lambda n]+1)}{(m-[\lambda m])(n-[\lambda n])}\left(\sigma_{m n}^{(11)}(u)\right. \\
& \left.-\sigma_{[\lambda m], n}^{(11)}(u)-\sigma_{m,[\lambda n]}^{(11)}(u)+\sigma_{[\lambda m],[\lambda n]}^{(11)}(u)\right) \\
& +\frac{[\lambda m]+1}{m-[\lambda m]}\left(\sigma_{m, n}^{(11)}(u)-\sigma_{[\lambda m], n}^{(11)}(u)\right) \\
& +\frac{[\lambda n]+1}{n-[\lambda n]}\left(\sigma_{m n}^{(11)}(u)-\sigma_{m,[\lambda n]}^{(11)}(u)\right) \\
& -\frac{1}{(m-[\lambda m])(n-[\lambda n])} \\
& \cdot \sum_{i=[\lambda m]+1}^{m} \sum_{j=[\lambda n]+1}^{n}\left(u_{m n}-u_{i j}\right) .
\end{aligned}
$$

Proof of Theorem 5. Let $u=\left(u_{m n}\right)$ be slowly oscillating; then, $\sigma_{m n}^{(k, r)}(u)$ is slowly oscillating (by Lemma 6). Further, since $u=$ $\left(u_{m n}\right)$ is $(C, k, r)$ summable to $s$, by Theorem 1 ,

$$
\lim _{m, n \rightarrow \infty} \sigma_{m n}^{(k, r)}(u)=s
$$

Next, from the definition,

$$
\sigma_{m n}^{(k, r)}(u)=\sigma_{m n}^{(1,1)}(u)\left(\sigma_{m n}^{(k-1, r-1)}(u)\right) .
$$

Clearly, (17) and (18) imply that $u=\left(u_{m n}\right)$ is $(C, k-1, r-1)$ summable to $s$. Again, $\left(\sigma_{m n}^{(k-1, r-1)}(u)\right)$ is also slowly oscillating (by Lemma 6).

Thus, by Theorem 1 , we have

$$
\lim _{m, n \rightarrow \infty} \sigma_{m n}^{(k-1, r-1)}(u)=s .
$$

Continuing in this way, we get $\lim _{m, n \rightarrow \infty}\left(u_{m n}\right)=s$

Remark 8. If $k=0$ and $r \neq 0$, then $(C, k, r)$ summability reduces to $(C, 0, r)$ summability. Again, for $k \neq 0$ and $r=$ $0,(C, k, r)$ summability reduces to $(C, k, 0)$ summability and, consequently, the following corollary is generated from the main result.

Corollary 9 (see [5]). If $u=\left(u_{n}\right)$ is $(C, 0, r)$ or $(C, k, 0)$ summable to $s$ and $u=\left(u_{n}\right)$ is slowly oscillating, then $\lim _{n \rightarrow \infty} u_{n}=s$.

Theorem 10. If $\left(u_{m n}\right)$ is $(C, k, r)$ summable to $s$ and $V_{m n}^{(11)}(\Delta u)$ is slowly oscillating, then $\lim _{m, n \rightarrow \infty} u_{m n}=s$.

Proof. As $V_{m n}^{(11)}(\Delta u)$ is slowly oscillating, setting $u=\left(u_{m n}\right)$ in place of $V_{m n}^{(11)}(\Delta u), \sigma_{m n}^{(k, r)}\left(V_{m n}^{(11)}(\Delta u)\right)$ is slowly oscillating by Lemma 6. Again, as $V_{m n}^{(11)}(\Delta u)$ is $(C, k, r)$ summable to $s$, by Theorem 3, we have

$$
\lim _{m, n \rightarrow \infty} \sigma_{m n}^{(k, r)}\left(V_{m n}^{(11)}(\Delta u)\right)=s
$$


By definition,

$$
\begin{aligned}
\sigma_{m n}^{(k, r)} & \left(V_{m n}^{(11)}(\Delta u)\right) \\
= & \sigma_{m n}^{(1,1)}\left(V_{m n}^{(11)}(\Delta u)\right)\left(\sigma_{m n}^{(k-1, r-1)}\left(V_{m n}^{(11)}(\Delta u)\right)\right) .
\end{aligned}
$$

From (20) and (21), we have that $V_{m n}^{(11)}(\Delta u)$ is $(C, k-1, r-1)$ summable to $s$. Again, by Lemma 6 , since $\left(\sigma_{m n}^{(k-1, r-1)}\left(V_{m n}^{(11)}(\Delta u)\right)\right)$ is slowly oscillating, we have $\lim _{m, n \rightarrow \infty} \sigma_{m n}^{(k-1, r-1)}\left(V_{m n}^{(11)}(\Delta u)\right)=s$ (by Theorem 3). Continuing in this way, we get $\lim _{m, n \rightarrow \infty}\left(V_{m n}^{(11)}(\Delta u)\right)=s$.

Remark 11. If $k=0$ and $r \neq 0$, then $(C, k, r)$ summability reduces to $(C, 0, r)$ summability. Again, for $k \neq 0$ and $r=$ $0,(C, k, r)$ summability reduces to $(C, k, 0)$ summability and consequently the following corollaries are generated from the main result.

Corollary 12 (see [5]). If $u=\left(u_{n}\right)$ is $(C, 0, r)$ summable to $s$ and $V_{m n}^{(1,0)}(\Delta u)$ is slowly oscillating, then $\lim _{n \rightarrow \infty} u_{n}=s$.

Corollary 13 (see [5]). If $u=\left(u_{n}\right)$ is $(C, k, 0)$ summable to $s$ and $V_{m n}^{(0,1)}(\Delta u)$ is slowly oscillating, then $\lim _{n \rightarrow \infty} u_{n}=s$.

\section{Competing Interests}

The authors declare that there are no competing interests regarding publication of this paper.

\section{References}

[1] F. Móricz, "Tauberian theorems for Cesàro summable double sequences," Studia Mathematica, vol. 110, no. 1, pp. 83-96, 1994.

[2] K. Knopp, "Limitierungs-Umkehrsätze für Doppelfolgen," Mathematische Zeitschrift, vol. 45, pp. 573-589, 1939.

[3] C. V. Stanojević, "Analysis of divergence control and management of divergent process," in Graduate Research Seminar Lecture Notes, İ. Çanak, Ed., University of Missouri-Rolla, Fall, 1998.

[4] Ü. Totur, "Classical tauberian theorems for the $(C ; 1 ; 1)$ summability method," Annals of theAlexandru Ioan Cuza UniversityMathematics, 2014.

[5] B. B. Jena, S. K. Paikray, and U. K. Misra, "A proof of Tauberian theorem for Cesàro summability method," Asian Journal of Mathematics and Computer Research, vol. 8, pp. 272-276, 2016.

[6] I. Çanak and Ü. Totur, "Some tauberian conditions for cesaro summability method," Mathematica Slovaca, vol. 62, no. 2, pp. 271-280, 2012.

[7] İ. Çanak, "A theorem on the Cesàro summability method," Computers \& Mathematics with Applications, vol. 61, no. 4, pp. 1162-1166, 2011.

[8] I. Çanak, "On means (C; 1) of sequences," Computers \& Mathematics with Applications, vol. 62, no. 9, pp. 3446-3448, 2011.

[9] İ. Çanak, "An extended Tauberian theorem for the (C,1) summability method," Applied Mathematics Letters, vol. 21, no. 1, pp. 74-80, 2008.

[10] İ. Çanak and Ü. Totur, "A Tauberian theorem for Cesàro summability of integrals," Applied Mathematics Letters, vol. 24, no. 3, pp. 391-395, 2011. 


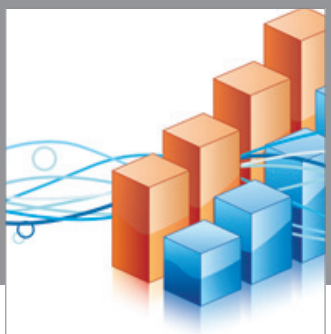

Advances in

Operations Research

vatem alat4

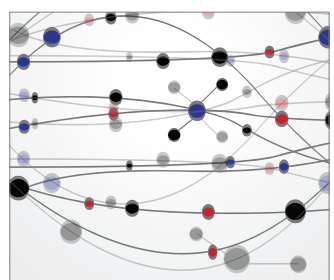

\section{The Scientific} World Journal
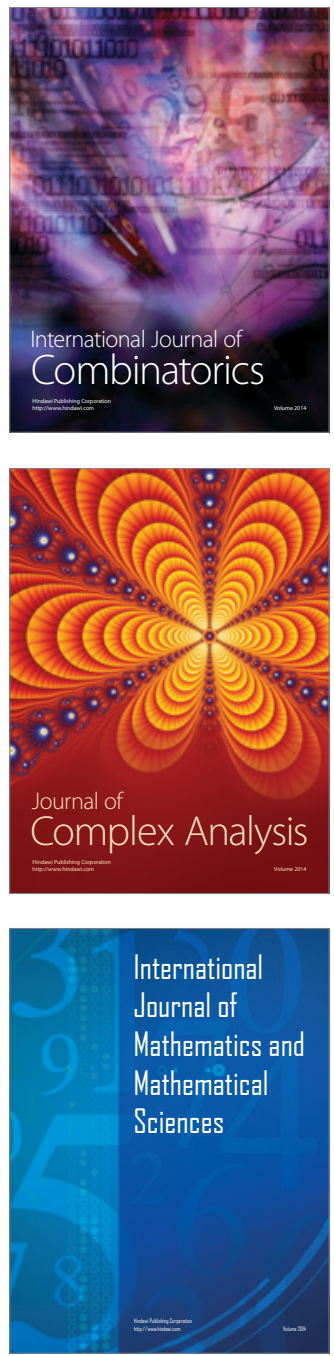
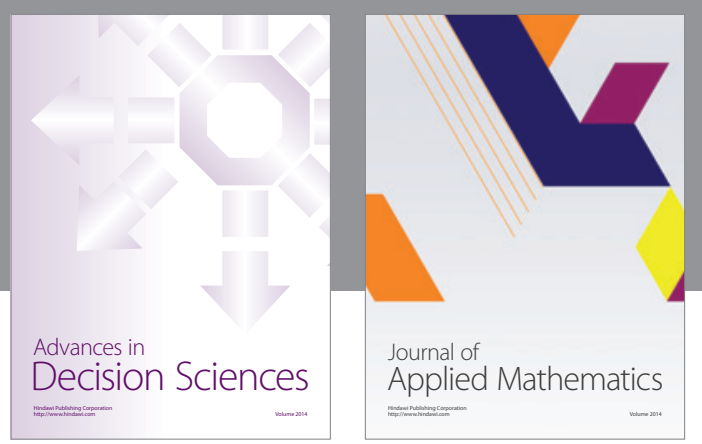

Algebra

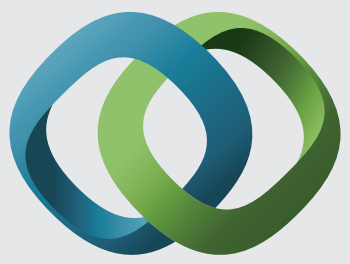

\section{Hindawi}

Submit your manuscripts at

http://www.hindawi.com
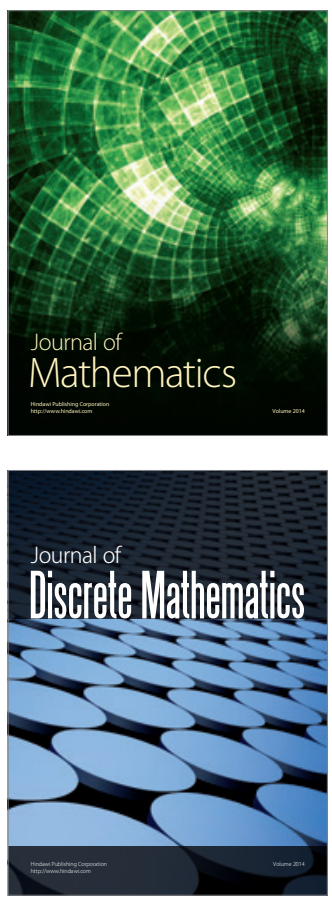

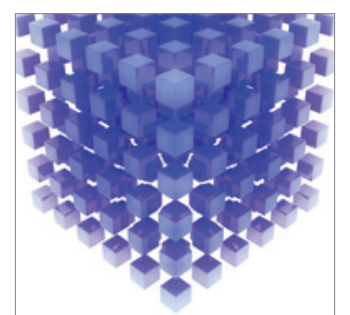

Mathematical Problems in Engineering
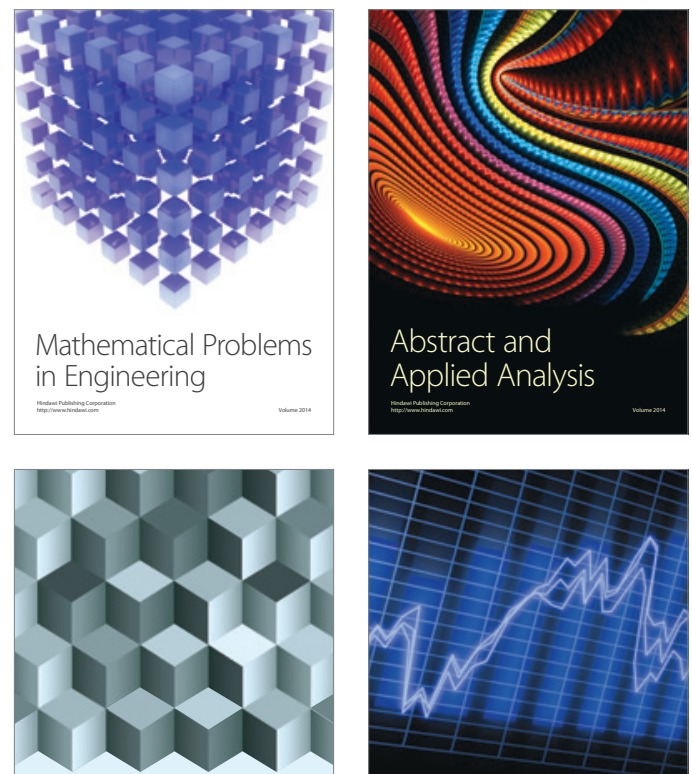

Journal of

Function Spaces

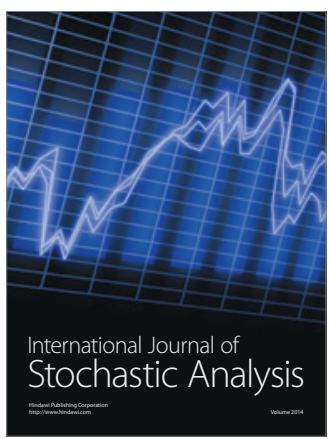

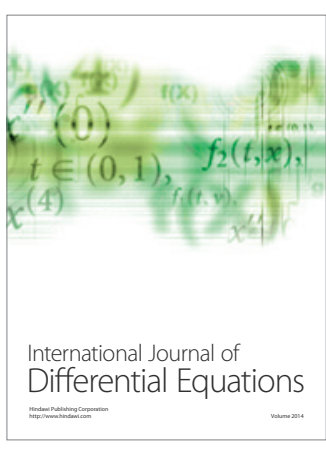
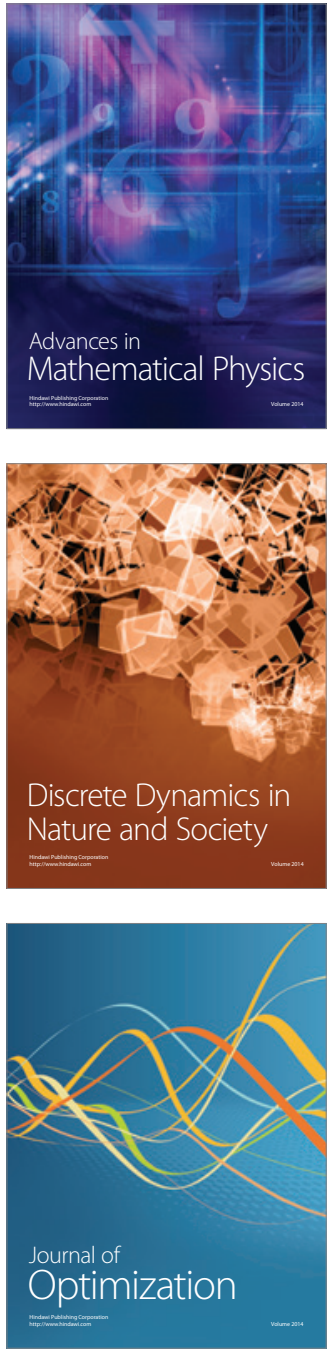